\title{
Plankton stress responses from PAH exposure and nutrient enrichment
}

\author{
M. Hjorth ${ }^{1,2, *}$, V. E. Forbes ${ }^{2}$, I. Dahllöf ${ }^{1}$ \\ ${ }^{1}$ Department of Marine Ecology, National Environmental Research Institute, University of Aarhus, Frederiksborgvej 399, \\ 4000 Roskilde, Denmark \\ ${ }^{2}$ Department of Environmental, Social and Spatial Change, Roskilde University, Universitetsvej 1, 4000 Roskilde, Denmark
}

\begin{abstract}
The hypothesis that the nature and force of PAH stress responses from plankton systems are coupled to the nutrient status of that system was tested in a mesocosm experiment. Four treatments were applied consisting of control $(\mathrm{Cn})$, pyrene exposed $(\mathrm{Py})$, nutrient spiked $(\mathrm{Nu})$, and nutrient spiked and pyrene exposed (NuPy) groups in replicate bags $(n=3)$ representing plankton communities including bacteria, phytoplankton and zooplankton. Regardless of nutrient status, all the Py mesocosms were affected directly with decreases in chlorophyll a concentrations to $20 \%$ of control values on Day 1. Primary production was also significantly lower $(<50 \%)$ than Cn communities in both Py and NuPy communities after the first pyrene exposure. Indirect effects were observed as increased bacterial activity due to nutrient release from algal death, thereby channelling growth to another trophic level. With time the plankton system became top-down controlled, dominated by zooplankton, which was also the trophic group experiencing the longest lasting effect on structure. The occurrence of late effects in the zooplankton communities were seen in all treatments, but the magnitude of the effects was dependent on the nutrient status, most probably because of a larger trophic transfer of the contaminant. To improve our understanding of contaminant effects on food webs in natural communities, it is imperative that interactions between trophic levels in relation to abiotic factors are investigated.
\end{abstract}

KEY WORDS: Plankton $\cdot$ PAH $\cdot$ Food web $\cdot$ Stress $\cdot$ Function $\cdot$ Nutrient status $\cdot$ Marine $\cdot$ Mesocosm

\section{INTRODUCTION}

The PAH pyrene has a detrimental effect on plankton communities at concentrations close to $3.4 \mathrm{nmol} \mathrm{l}^{-1}$ (Hjorth et al. 2007), which is the lower ecotoxicological assessment criteria (EAC) recommended by the Oslo Paris Commission (Bignert et al. 2004). The same study implied that the type of response from plankton systems to PAH stress was coupled to the status of nutrients and availability of substrate in the system. If nutrients were scarce and limiting production, direct biological effects from pyrene exposure could be concealed in nutrient releases from indirect effects, and the strength of exposure of pyrene to higher trophic levels may also be linked to biomass concentrations (Hjorth et al. 2007). To assess the extent to which stress from high nutrient loads compare and interact with the effects of PAHs on plankton communities, the present study was designed to test whether stress responses from plankton systems to pyrene exposure would be stronger if the initial nutrient status of the plankton community was high.

The focus on a link between sensitivity towards contaminants and nutrient levels is not new, and has especially been studied extensively in freshwater systems (Cloern 2001, Koelmans et al. 2001), but specific knowledge of how stress from contaminants and high nutrient levels interact in the marine environment is scarce (Sundbäck et al. 2007). It may be even more urgent to investigate the relationship between contaminant stress response and nutrient loads, since increased nutrient release to coastal systems is a recognized consequence of climate change (Harley et al. 2006). In that perspective it is imperative to gain more 
knowledge on interactions between pollution effects and climate change (Macdonald et al. 2005).

How contaminant stress like PAH exposure affects a plankton system is partly determined by the structure and controlling factors of the food web. The productivity can be bottom-up controlled, with abiotic conditions such as light, temperature and nutrients determining production rates, and where PAH exposure may affect primary producers more severely under these conditions. This was the case as determined by Hjorth et al. (2007) who suggested phytoplankton are the most susceptible group, and declines in their biomass and/or activity lead to indirect effects in bacterial and zooplankton communities. On the other hand, a system can be top-down controlled where primary production is limited by predation from other trophic levels. This is a more complex situation and contaminant stress responses might be more difficult to predict (Koelmans et al. 2001).

Interactions between nutrient and contaminant stress in a plankton system can occur through several mechanisms. Increased biomass resulting from a nutrient influx can result in a dilution of contaminants, more contaminants bound in dissolved organic matter (DOM), increased sedimentation of contaminants and increased uptake and transfer in food webs. Interactions may predict both lesser and stronger sensitivity towards contaminants in systems with abundant or excess nutrients (Skei et al. 2000).

Increase in biomass as a consequence of more nutrients may include a change in community composition compared with nutrient limited systems (Interlandi 2002) and biodiversity changes may in turn result in changes in community response to contaminant exposure. Such direct and indirect effects on function and structure can cause cascading effects to other trophic levels and affect, for example, zooplankton community structure and composition through prey quality and availability (Preston 2002, Fleeger et al. 2003).

These considerations give rise to a multitude of questions about the importance of food web structure as a governing factor for plankton community response to contaminants and nutrient changes. This study investigates specifically whether a difference exists in type and strength of selected structural and functional responses to pyrene exposure of plankton communities, which only differ in initial inorganic nutrient status. To address these questions, a mesocosm design was used with randomized replicate bags $(\mathrm{n}=3)$ with 4 treatments: control $(\mathrm{Cn})$, exposure to $50 \mathrm{nmol} \mathrm{l}^{-1}$ pyrene (Py), nutrient enrichment (Nu) and both pyrene exposure and nutrient enrichment (NuPy). Treatments were administered 2 times during a $2 \mathrm{wk}$ period to obtain a scenario where plankton communities having 2 levels of nutrient status respond to pulse exposures of pyrene.

\section{MATERIALS AND METHODS}

The mesocosm experiment was carried out in the Isefjord, Denmark (average depth 5 to $7 \mathrm{~m}$ ), for $12 \mathrm{~d}$ in April and May 2005 in a similar manner as described in Hjorth et al. (2007). Twelve mesocosm bags $\left(3 \mathrm{~m}^{3}\right)$ were established, creating 3 replicate mesocosms per experimental treatment. Temperature in the bags varied between 10 and $15^{\circ} \mathrm{C}$, and the salinity was constant at $16 \mathrm{psu}$. Mixing was provided by an airlift system (Egge \& Heimdal 1994) as well as by natural water motion outside the bags. After $2 \mathrm{~d}$ of acclimatization, $\mathrm{Nu}$ and NuPy mesocosms were spiked with nutrients (i.e. Day -1) and again on Day 6, and pyrene was added on Day 0 and Day 7 . The $1 \mathrm{~d}$ time lag between addition of nutrients and pyrene was intended to allow the plankton systems to respond to nutrients alone, before they were exposed to pyrene. Inorganic nutrients were added to obtain final concentrations of $8 \mu \mathrm{mol} \mathrm{l}^{-1} \mathrm{am}$ monia $\left(\mathrm{NH}_{3} \mathrm{Cl}\right), 4.6 \mu \mathrm{mol} \mathrm{l} \mathrm{l}^{-1}$ silicate $\left(\mathrm{Na}_{2} \mathrm{SiO}_{3}\right)$ and $0.6 \mu \mathrm{mol} \mathrm{l}{ }^{-1}$ phosphate $\left(\mathrm{NaH}_{2} \mathrm{PO}_{4}\right)$. Pyrene was added in nominal concentrations of $50 \mathrm{nmol}^{-1}$ to the relevant bags under intense stirring after nightfall to avoid phototoxic effects of pyrene. Pyrene was dissolved in $100 \mathrm{ml}$ acetonitrile (Merck). The solvent concentration did not exceed $3 \mu \mathrm{g}^{-1}$ in any of the bags. The exposure concentration was chosen on the basis of previous results from mesocosm experiments on natural plankton communities (Hjorth et al. 2007).

Sampling. All variables were measured prior to the addition of pyrene (Day 0 ) and on each day for the next 5 consecutive days and from then on every second day. Nutrient samples were also taken immediately before and after spiking with nutrients $1 \mathrm{~d}$ prior to the first pyrene exposure. Depth integrated water samples were taken with a total of 1441 sampled water from each mesocosm bag during the whole experiment, which amounts to $\sim 5 \%$ of the total volume. Sampled water was gently filtered through a $45 \mu \mathrm{m}$ sieve to collect larger zooplankton, which were used for analyses of abundance. From the filtered water, 51 subsamples were taken ashore immediately for all other analyses, and the remaining $11 \mathrm{l}$ were discarded.

Pyrene analysis. Concentrations of pyrene in the water column were measured immediately after its addition, $1 \mathrm{~h}$ later and at $24 \mathrm{~h}$ intervals until $96 \mathrm{~h}$ (Day 4) during the experiment. Water from $0.5 \mathrm{~m}$ depth was collected in brown glass flasks and warmed to room temperature. A Varian Eclipse fluorescence spectrophotometer was used for measuring fluorescence excitation emission matrices (EEMs). For details concerning instrument setup and data analysis, consult Hjorth et al. (2007). The detection limit of the assay was $5 \mathrm{nmol} \mathrm{l}^{-1}$ and the relative standard of deviation at $10 \mathrm{nmol} \mathrm{l}^{-1}$ was $8.8 \%$. 
Nutrients. A $30 \mathrm{ml}$ water sample from each bag was kept frozen until analysis of $\mathrm{Si}, \mathrm{PO}_{4}, \mathrm{NH}_{4}$ and $\mathrm{NO}_{3}$ on a Skalar autoanalyser (Breda, Netherlands) according to Andersen et al. (2004).

Chlorophyll a. Phytoplankton biomass was determined as the relative concentration of chlorophyll $a$ (chl a) compared with the controls. A $50 \mathrm{ml}$ sample from each treatment was vacuum-filtered through a GF/F filter, extracted in $5 \mathrm{ml} 96 \%$ ethanol for $24 \mathrm{~h}$ and fluorometrically analysed (10-AU Turner fluorometer).

Phytoplankton activity. The functional endpoint for the phytoplankton was $\mathrm{H}^{14} \mathrm{CO}_{3}^{-}$incorporation as an estimate of primary production. From each mesocosm subsample, 4 replicates of $10 \mathrm{ml}$ were taken with a $10 \mathrm{ml}$ automatic kip dispenser pipette (Schott Duran) and incubation and analysis were performed as described in Hjorth et al. (2007). Mean values of the triplicate control mesocosm bags were set to $100 \%$ activity. Specific primary production was estimated as the total incorporation divided by the amount of chl a.

Pigment analysis. On Days 1, 5 and 10, 100 to $250 \mathrm{ml}$ of water were gently filtered through $25 \mathrm{~mm}$ Advantec GF 75 glass fibre filters (Toyo Roshi Kaisha) and immediately stored in liquid nitrogen. Pigments were subsequently extracted, identified and quantified as described in Hjorth et al. (2007).

Bacterial activity. Bacterial community activity was monitored as protein synthesis activity by daily measurements of ${ }^{14} \mathrm{C}$-labelled leucine incorporation. A modified version of Smith and Azam's (1992) centrifugation $\left[{ }^{14} \mathrm{C}\right]$-leucine incorporation method was applied and described in Hjorth et al. (2007). The mean value of the control mesocosm bags was set to $100 \%$ activity.

Copepod abundance. Zooplankton were collected from $45 \mu \mathrm{m}$ filters, through which the daily depth integrated water samples were filtered, and the zooplankton were preserved in formalin $(0.4 \%$ final concentration) in brown glass flasks and refrigerated at $5^{\circ} \mathrm{C}$. Samples were analyzed within 2 mo of sampling. Copepods and copepodites were identified to genus or species level, counted and pooled in 1 group as an estimate of mesozooplankton.

Statistical analysis. For each functional variable, the data set consisted of daily mean values $(n=4)$ from each mesocosm bag. When testing for differences between means of control and treatments $(n=3)$, a 2factor ANOVA for repeated samplings with Dunnett's 2-tailed $t$-test as a post hoc test was performed after testing for homogeneity of variances (Cochran's test) using SAS software (v. 8.02). Multivariate analysis of pigment and zooplankton data was performed in PRIMER software, using square root transformation for zooplankton data. In all statistical analyses changes were defined to be significant when $\mathrm{p}<0.05$ and marginally significant when $0.05<\mathrm{p}<0.1$.

\section{RESULTS \\ Pyrene}

Nominal concentrations of $50 \mathrm{nmol} \mathrm{l}^{-1}$ pyrene added to the 6 Py mesocosm bags resulted in measured concentrations of $58 \pm 18 \mathrm{nmol} \mathrm{l}^{-1}$ (95\% confidence limits, $\mathrm{n}=6$ ) immediately after addition on Day 0 (Fig. 1). After 2 d concentrations were below the detection limit of $5 \mathrm{nmol} \mathrm{l}^{-1}$. On Day 7 , immediately after the second addition of $50 \mathrm{nmol} \mathrm{l}^{-1}$ nominal concentrations, measured concentrations were $79 \pm$ $10 \mathrm{nmol} \mathrm{l}^{-1}(95 \%$ confidence limits, $\mathrm{n}=6)$ and fell below the detection limit after $2 d$, on Day 9. The reductions in pyrene concentrations over time could be due to both degradation and adsorption to mesocosm walls and particles, as discussed in another mesocosm experiment with a similar setup performed by Hjorth et al. (2007).

\section{Nutrients}

The nutrient treatments led to similar concentrations and dynamics in both $\mathrm{Nu}$ and NuPy communities. For the sake of simplicity we only show data from control $(\mathrm{Cn})$ and enriched communities $(\mathrm{Nu})$ without pyrene exposure (Fig. 2). Initial concentrations of nutrients were low $\left(\mathrm{PO}_{4}, 0.1\right.$ to $0.3 \mu \mathrm{mol} \mathrm{l}^{-1} ; \mathrm{Si}, 2.8$ to $3.0 \mu \mathrm{mol} \mathrm{l}^{-1}$; $\mathrm{NH}_{3}, 0.7$ to $1.0 \mu \mathrm{mol} \mathrm{l^{-1 }}$ ), except for nitrate (18.6 to $19.2 \mu \mathrm{mol} \mathrm{l}^{-1}$ ). The first addition of nutrients increased phosphate concentrations to $0.5-0.6 \mu \mathrm{mol}^{-1}$, silicate to 4.3-4.6 $\mu \mathrm{mol} \mathrm{l^{-1 }}$ and ammonia to $8 \mu \mathrm{mol} \mathrm{l^{-1 }}$. Ammonia was the preferred source of nitrogen in the $\mathrm{Nu}$ and NuPy communities, where concentrations decreased to levels of the non-enriched communities by Day 1,

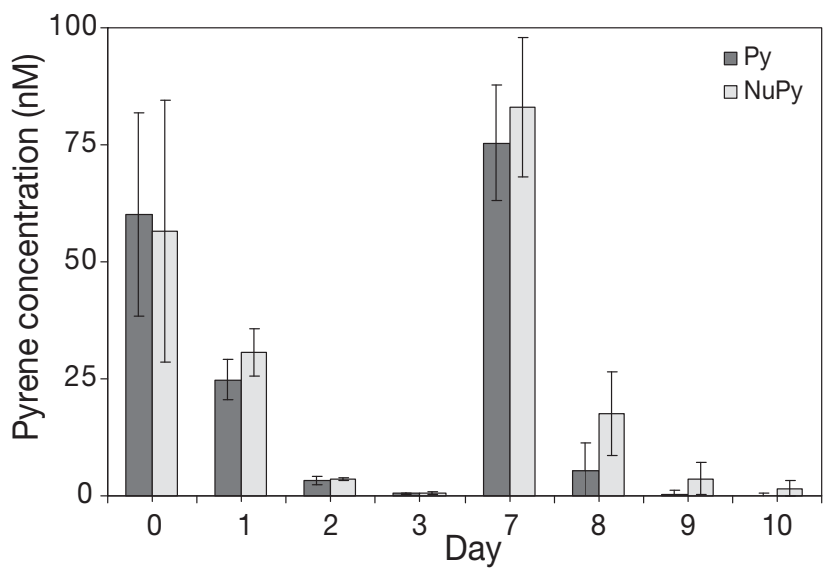

Fig. 1. Concentration of pyrene in the mesocosm bags from additions of $50 \mathrm{nM}$ on Day 0 and Day 7. Data are shown as means $\pm 95 \%$ confidence intervals $(n=3)$. Py: pyrene exposure; NuPy: nutrient enrichment + pyrene exposure 


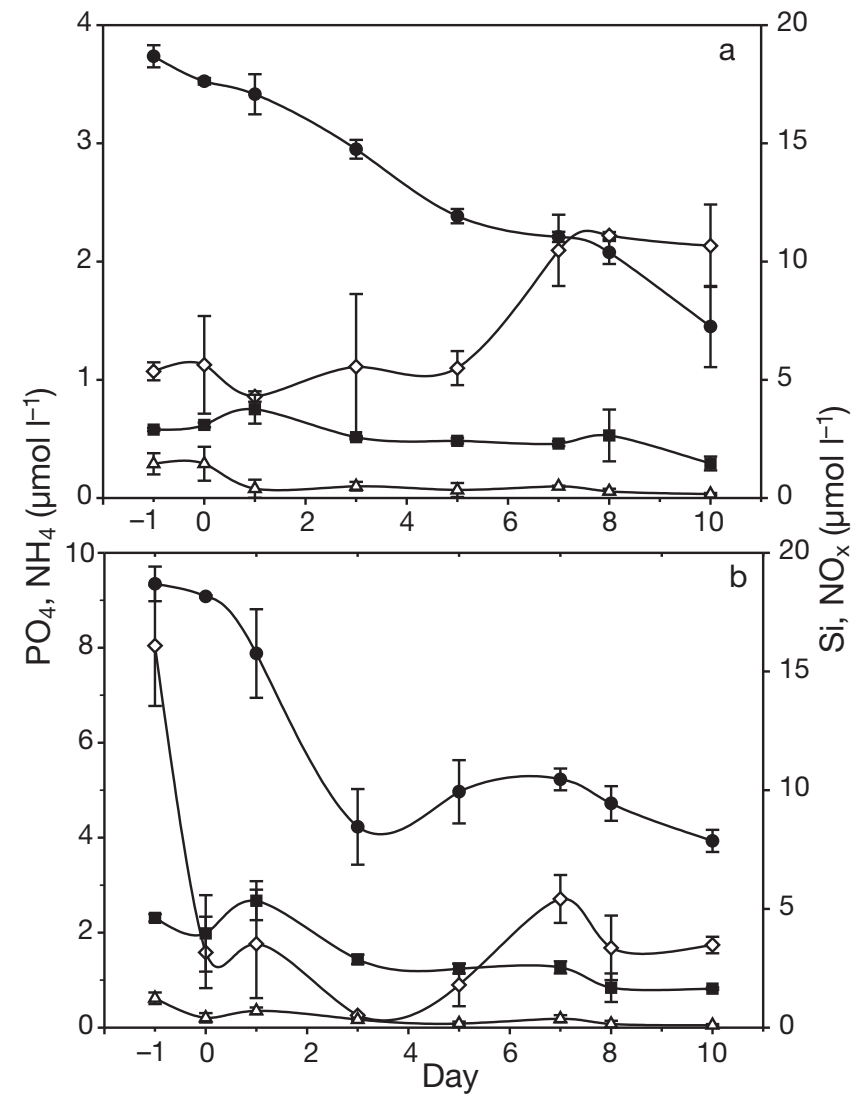

Fig. 2. Mean $\pm \mathrm{SD}(\mathrm{n}=3)$ nutrient concentrations in (a) control and (b) nutrient enriched communities during the mesocosm experiment. $\diamond=\mathrm{NH}_{4}, \Delta=\mathrm{PO}_{4}, \boldsymbol{\square}=\mathrm{Si}$ and $\bullet=\mathrm{NO}_{2}+\mathrm{NO}_{3}$ $\left(\mathrm{NO}_{\mathrm{x}}\right)$. Note different scales on $y$-axis

whereas nitrate was the preferred substrate in the $\mathrm{Cn}$ and Py communities. Nitrate subsequently sustained phytoplankton growth in the $\mathrm{Nu}$ and $\mathrm{NuPy}$ treatments between Days 2 and 4, and phosphate concentrations reached the levels of the non-enriched communities on Day 3. On Day 7 there was a release of $\mathrm{NH}_{4}{ }^{+}$in controls. Silicate concentrations in the nutrient-enriched communities stayed above concentrations of the nonenriched communities until Day 5. The second addition of nutrients on Day 6 was only reflected in ammonia concentrations, whereas ammonia and silicate concentrations stayed within range of concentrations in the non-enriched communities.

\section{Chlorophyll a}

The plankton system was nutrient limited from the beginning of the mesocosm experiment, and the applied nutrient enrichment doubled the biomass of phytoplankton, which resulted in 2 systems different in phytoplankton biomass already on Day 0. Chl a concentrations in $\mathrm{Nu}$ and $\mathrm{NuPy}$ communities was 1.75 times higher than in $\mathrm{Cn}$ and Py communities on Day 0 (Fig. 3a). The Nu treatment sustained a higher chl a concentration throughout the experiment, with maximum chl a concentrations evident on Day 1 and on Day 2, which declined to a minimum level of $2.0 \mathrm{\mu g} \mathrm{l}^{-1}$ on Day 10 for the $\mathrm{Nu}$ communities. In both pyrene treated communities, a direct effect was observed in concentrations of chl $a$, regardless of nutrient status. In the Py communities chl a concentrations were approximately $20 \%$ of those in Cn communities on Day 1 (Fig. 3b) and stayed significantly lower than in the Cn communities until Day 5. In the NuPy communities the chl a concentrations decreased to the same levels as in Py communities on Day 1, but from a higher starting point. After the initial sharp decline the NuPy communities were only significantly lower than the Cn communities until Day 2.
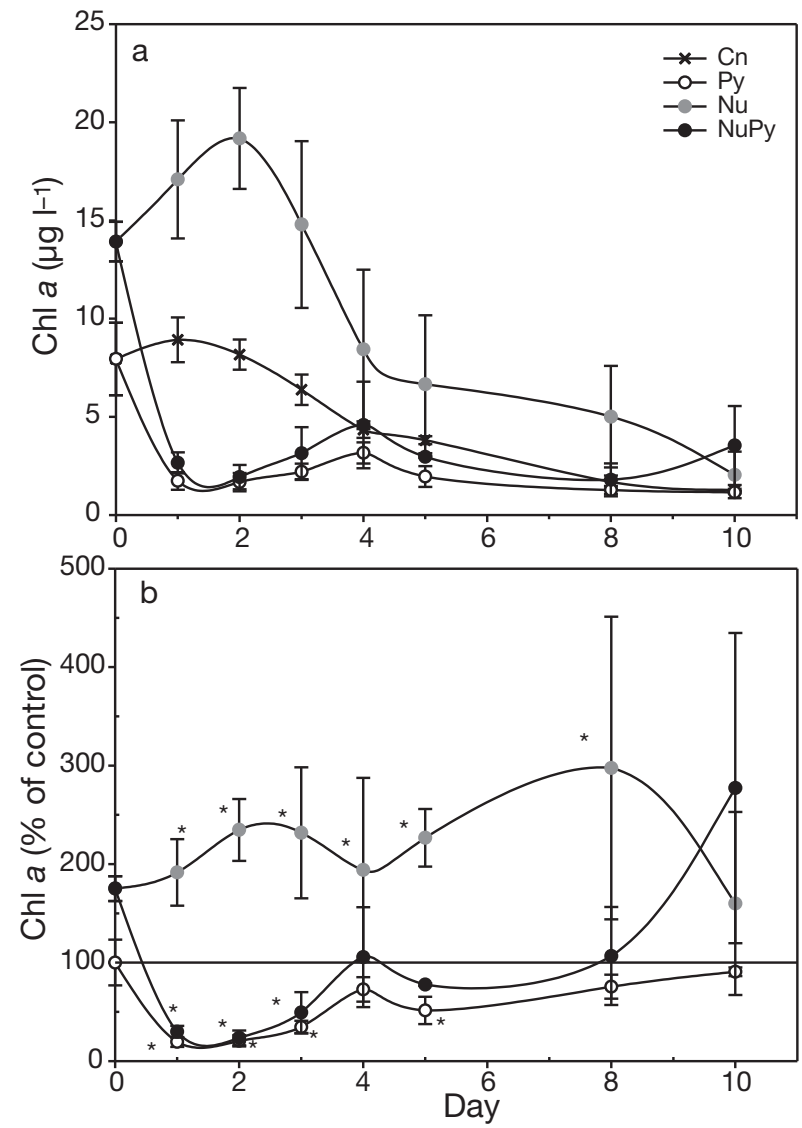

Fig. 3. Chl a concentrations during the mesocosm experiment. (a) Absolute values of chl a $\left(\mu \mathrm{gl}^{-1}\right)$ are shown as means $\pm \mathrm{SD}$ $(\mathrm{n}=3)$. (b) Relative values shown as percent of control communities. $\mathrm{Cn}, \mathrm{Nu}, \mathrm{Py}$ and NuPy: control, nutrient, pyrene and nutrient + pyrene treatments, respectively (see 'Introduction'). ${ }^{*}$ Significant differences from control communities $(\mathrm{p}<0.05)$ 

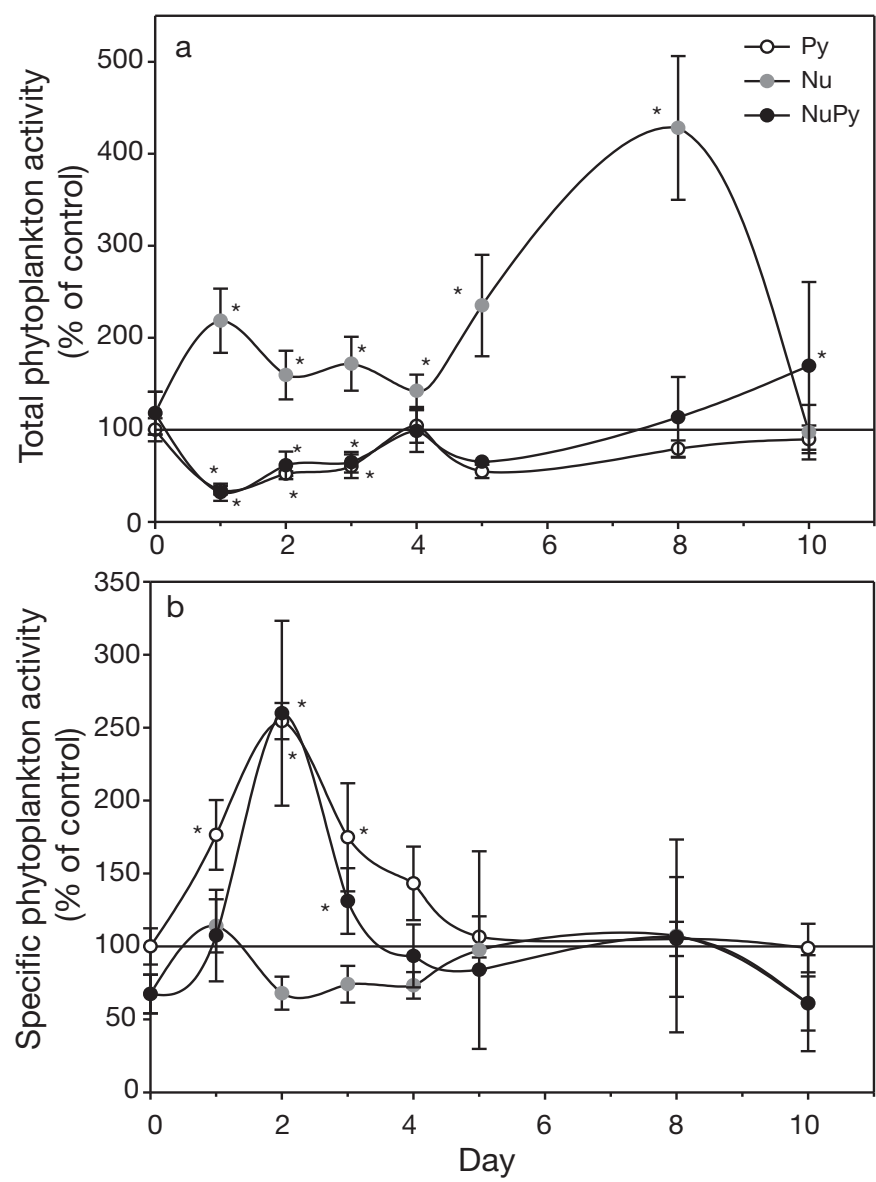

Fig. 4. Mean \pm SD $(n=3)$ phytoplankton activity in treated communities (Py: pyrene exposure; Nu: nutrient-enriched; $\mathrm{NuPy}$ : $\mathrm{Nu}+\mathrm{Py}$ ) during the mesocosm experiment as percent of control. (a) Total community activity of phytoplankton and (b) specific activity. *Significant differences from control communities $(\mathrm{p}<0.05)$

\section{Phytoplankton activity}

The addition of nutrients increased total primary production in the $\mathrm{Nu}$ communities, reaching a high maximum of $400 \%$ of Cn community levels on Day 8 (Fig. 4a). Total primary production was significantly reduced $(>50 \%)$ in both NuPy and Py communities after the first pyrene exposure compared with the control communities (Fig. 4a), which lasted until Day 3. Effects of the second exposure to pyrene were only detectable in the Py communities on Day 8, which had a significantly lower primary production compared with the $\mathrm{Cn}$ communities. The primary production in NuPy communities became significantly higher than in the Cn communities on Day 10.

The specific primary production increased above control levels immediately after pyrene exposure on Day 1 in the Py communities and reached a maximum of $254 \%$ of the specific primary production in the $\mathrm{Cn}$ communities on Day 2 (Fig. 4b). Specific primary production in the NuPy communities also reached a maximum (260\%) on Day 2. In both Py and NuPy communities, the specific primary production decreased thereafter to Cn community levels on Day 4, where it stayed for the remainder of the experiment. Nutrient treatment alone $(\mathrm{Nu})$ did not affect specific primary production of the phytoplankton during the experiment.

\section{Phytoplankton structure}

Pigment composition analysis revealed a dominance of diatoms, dinoflagellates and cryptophytes in all mesocosm bags during the whole experiment (>95\% of total). On Day 1 the communities segregated from each other according to pyrene exposure and not nutrient status. The Nu communities were not significantly different from the $\mathrm{Cn}$ communities in phytoplankton composition at any time during the experiment (13 to $14 \%$ dissimilarity). Cn communities consisted approximately of one-third of each of the 3 dominant groups on Day 1, and $\mathrm{Nu}$ communities resembled them closely, although with a slightly higher abundance of dinoflagellates (Fig. 5). Only the Py communities were significantly different compared with Cn communities, with an increase in diatom abundances (Py, 68\% of total abundance) and a decrease in dinoflagellate and cryptophyte abundances, but only on Day 1 . There were also tendencies for changes in NuPy communities on Day 10 as well, but the changes were not significantly different compared with $\mathrm{Cn}$ communities.

\section{Bacterial activity}

Bacterial activity was not significantly affected by the nutrient treatment alone, but in the Py and NuPy communities the bacterial activity was significantly higher than in the Cn communities on Day 2 (Fig. 6). After the second exposure to pyrene (Day 8), a slight increase in activity was observed only in the NuPy communities.

\section{Zooplankton}

Zooplankton samples were counted and individuals were identified to group level and for copepods to species level and life stage. Individuals of Acartia spp. and Centropages hamatus comprised $>90 \%$ of the abundance of adult copepods and copepodites in all of the plankton communities (Fig. 7). Rotifers were numerically the most abundant group, followed by polychaete 
larvae and copepod nauplii in all mesocosms. Abundance of copepods and copepodites in $\mathrm{Nu}$ and $\mathrm{Cn}$ communities were initially low, but increased during the experiment to maximum adult copepod abundance on Day 12 with $107 \pm 28$ ind. $\mathrm{l}^{-1}$ (mean $\pm \mathrm{SD}, \mathrm{n}=3$ ) and

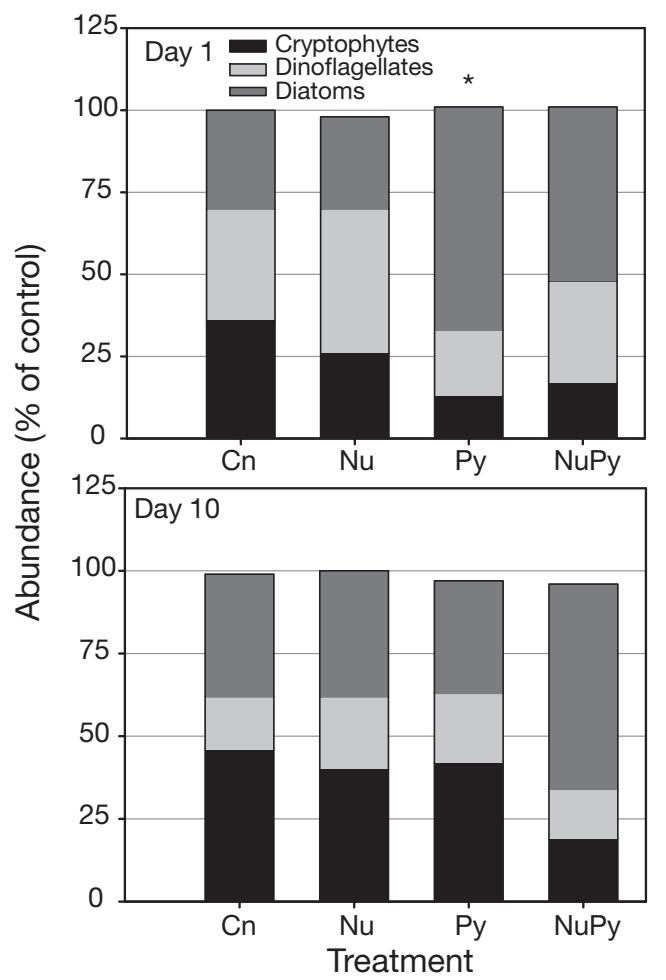

Fig. 5. Percentage of total abundance of phytoplankton groups in plankton communities on Day 1 and Day 10 derived from pigment data. *Significant differences from control $(\mathrm{Cn})$ communities $(\mathrm{p}<0.05)$

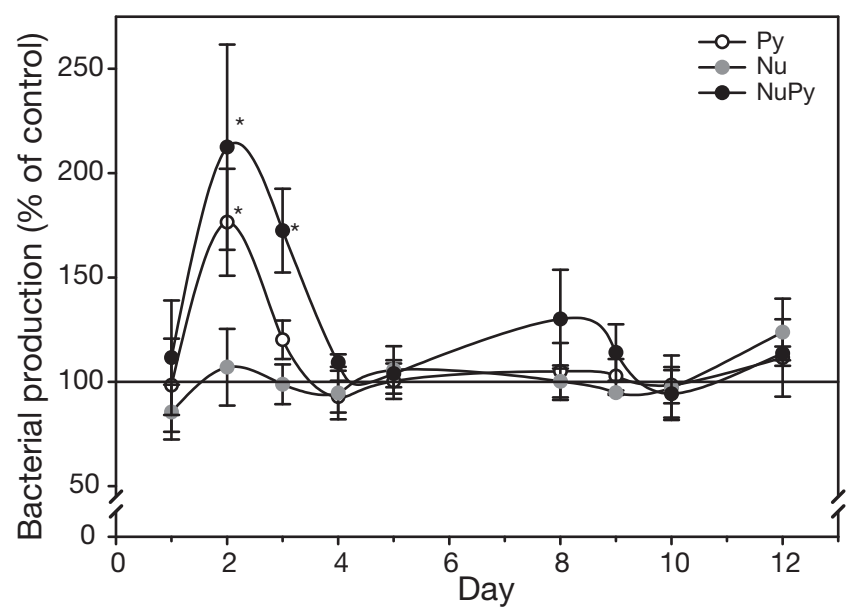

Fig. 6. Bacterial activity in treated (Py: pyrene-exposed; Nu: nutrient-enriched; $\mathrm{NuPy}: \mathrm{Nu}+\mathrm{Py}$ ) communities during the mesocosm experiment as percent of control communities. Data are shown as means \pm SD $(n=3)$. * Significant differences from control communities $(p<0.05)$
$57 \pm 8$ ind. $\mathrm{l}^{-1}(\mathrm{n}=3)$ in the $\mathrm{Cn}$ and $\mathrm{Nu}$ and communities, respectively (Fig. 8). During the course of the experiment, the abundance in the pyrene exposed communities did not increase to the same extent as it did in the control communities. In the end, the total number of adult individuals was up to 4 times lower in NuPy communities than in Cn communities. Rotifers increased to a maximum on Day 1 in Py communities and on Day 3 in $\mathrm{Cn}$ and $\mathrm{Nu}$ communities. In NuPy communities rotifer numbers decreased all through the experiment (Fig. 9). Gastropod and bivalve larvae were present in all mesocosms in low numbers, while polychaete larval abundance increased during the experiment in all treatments ending with the highest numbers in the Py communities. Using multivariate statistics, similarity indices were generated based on square root transformed zooplankton data, where the similarities of treated communities to control communities are expressed in percent (Table 1). On Day 1 all treated communities were significantly different from $\mathrm{Cn}$ communities regardless whether the analyses were based on the total zooplankton communities or on adult copepods, copepod nauplii or invertebrate larvae separately. All treatments were significantly different from Cn communities on all the selected days when analysing the whole zooplankton community (data not shown). Invertebrate larvae seemed to be least sensitive to pyrene exposure

Table 1. Similarity between treated (Py: pyrene-exposed; Nu: nutrient-enriched; NuPy: $\mathrm{Nu}+\mathrm{Py}$ ) and control communities based on square root transformed zooplankton abundance data from selected days. Percent similarity is listed with $95 \%$ confidence interval in parentheses for adult copepods (Fig. 7), copepod nauplii and invertebrate larvae (Fig. 9). "Significantly different from control at $p<0.05$ (repeated measurements ANOVA with a Dunnett's post hoc $t$-test)

\begin{tabular}{|lccc|}
\hline \multirow{2}{*}{ Day } & \multicolumn{3}{c}{ \% Similarity to control } \\
& $\mathrm{Nu}$ & NuPy & $\mathrm{Py}$ \\
\hline Adult copepods & & & \\
1 & $74(14)^{*}$ & $79(3)^{*}$ & $73(6)^{*}$ \\
3 & $77(24)$ & $77(31)$ & $82(23)$ \\
8 & $82(25)$ & $74(24)^{*}$ & $82(22)$ \\
10 & $85(9)^{*}$ & $77(16)^{*}$ & $85(8)^{*}$ \\
12 & $87(16)$ & $69(19)^{*}$ & $83(13)^{*}$ \\
Copepod nauplii & & & \\
1 & $80(11)^{*}$ & $80(18)^{*}$ & $80(12)^{*}$ \\
3 & $75(31)$ & $83(27)$ & $80(12)$ \\
8 & $78(29)$ & $75(12)$ & $79(10)$ \\
10 & $80(4)^{*}$ & $80(5)^{*}$ & $68(2)^{*}$ \\
12 & $87(6)^{*}$ & $82(5)^{*}$ & $71(12)^{*}$ \\
Invertebrate larvae & & & \\
1 & $84(5)^{*}$ & $72(2)^{*}$ & $74(1)^{*}$ \\
3 & $84(8)$ & $83(10)$ & $77(8)^{*}$ \\
8 & $83(9)$ & $87(7)$ & $84(11)$ \\
10 & $89(5)$ & $86(3)$ & $74(9)^{*}$ \\
12 & $85(7)^{*}$ & $90(4)$ & $82(5)^{*}$ \\
\hline
\end{tabular}



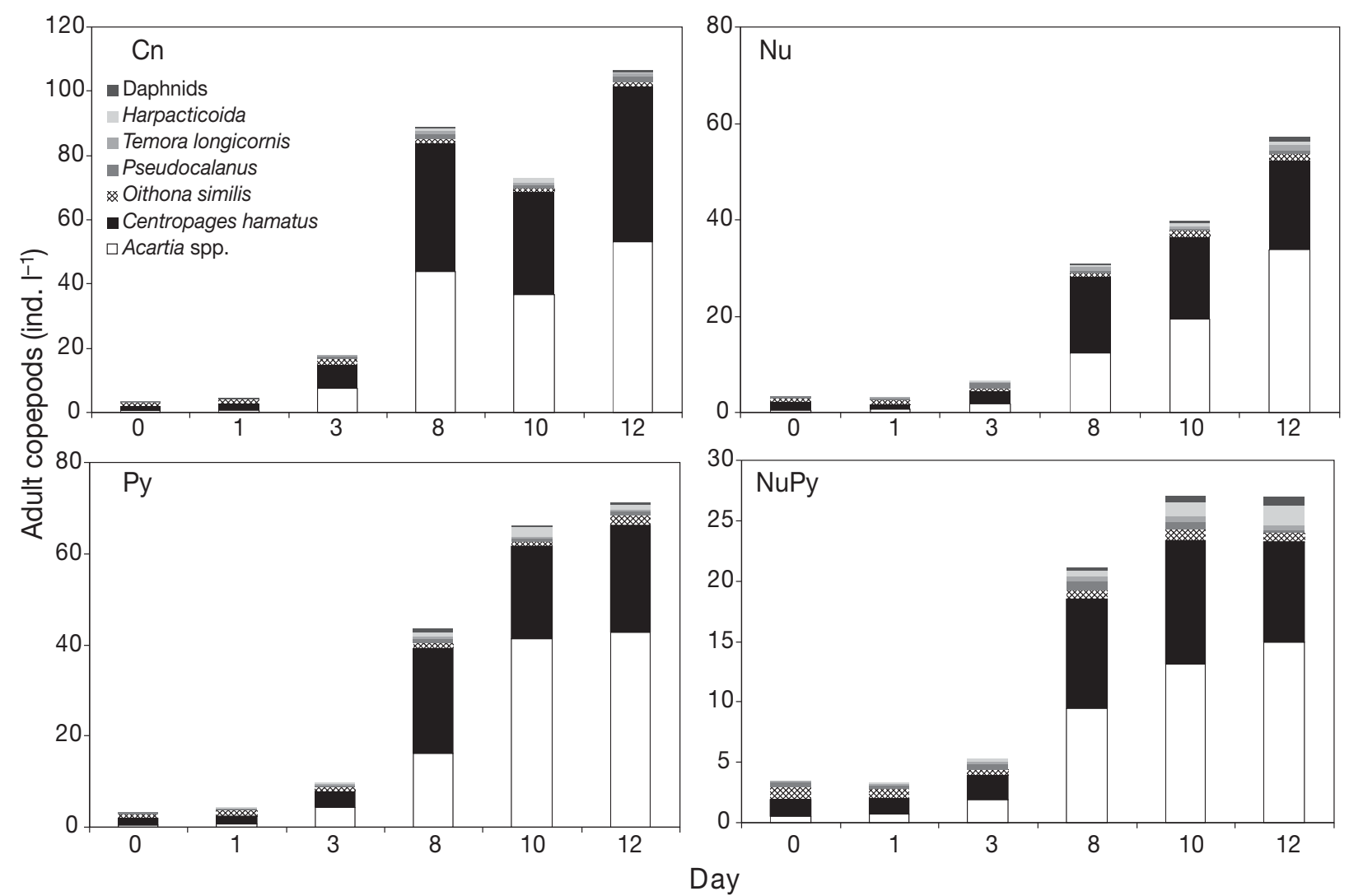

Fig. 7. Mean $\pm \mathrm{SD}(\mathrm{n}=3)$ abundance of dominating species of adult copepods, copepodites and Daphnia in control (Cn), nutrient-enriched $(\mathrm{Nu})$, pyrene-exposed $(\mathrm{Py})$, and $\mathrm{Nu}+\mathrm{Py}(\mathrm{NuPy})$ communities on selected days of the experiment. Note different scales on $y$-axis

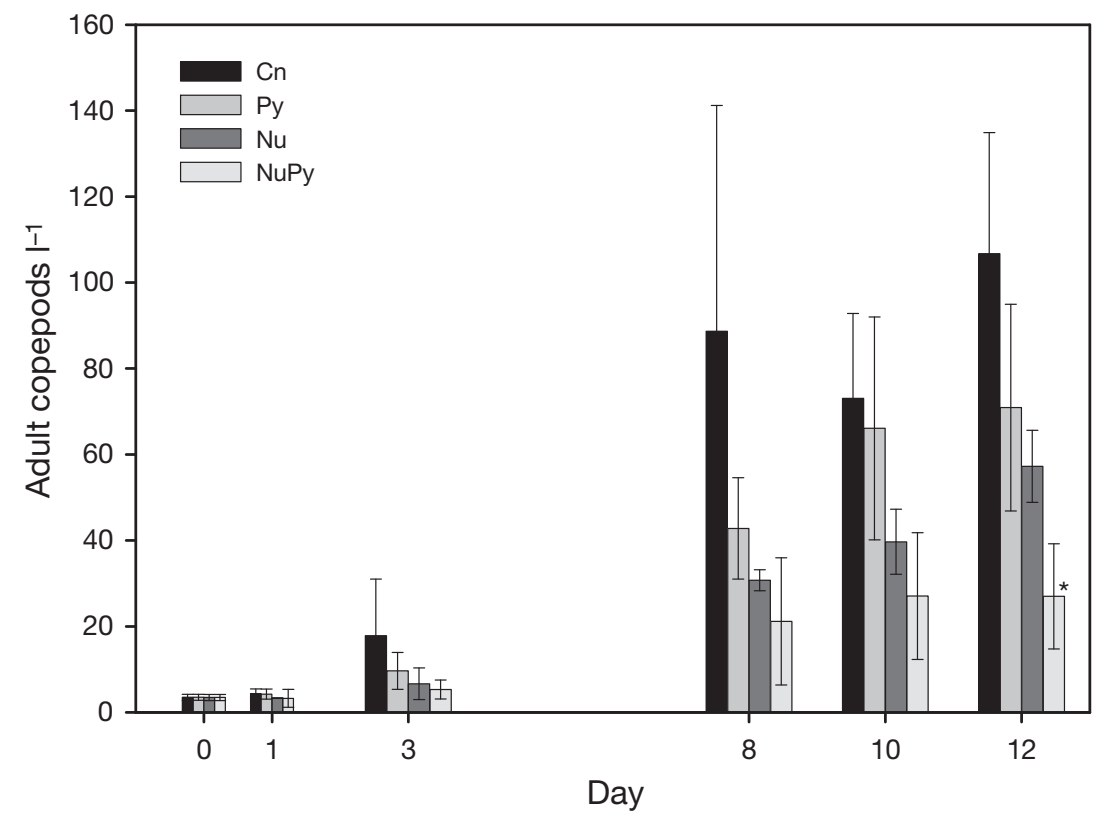

Fig. 8. Mean \pm SD $(n=3)$ abundance of adult copepods in the plankton communities on selected days during the experiment. *Significant difference from control communities $(\mathrm{p}<0.05)$ alone (Py community), whereas adult copepods showed the highest sensitivity towards pyrene and nutrient exposure in combination (NuPy community).

\section{DISCUSSION}

The hypotheses that the response from a plankton community to $\mathrm{PAH}$ stress is coupled to the nutrient status of that system and the strength of exposure is linked to biomass concentrations were confirmed. The plankton communities went from being bottomup to top-down controlled, and effects were always the highest for the controlling part of the communities, phytoplankton in the beginning and zooplankton towards the end. It has been suggested that predicting contaminant stress responses might be more difficult when the system is top-down con- 
trolled (Koelmans et al. 2001), and that food-web interactions may lead to predictions of both lesser and stronger sensitivity towards contaminants in systems with abundant or excess nutrients (Skei et al. 2000). However, this study, together with our previous work (Hjorth et al. 2007), shows that effects of pyrene in more complex test systems can be reproduced and similar patterns of structural and functional responses can be observed on plankton communities with different initial composition and functional status. Our assumption of a stronger effect of pyrene on plankton communities with high nutrient status was most clearly the case for phytoplankton biomass and activity, less evident for zooplankton and not valid for bacteria. In contrast, stronger effects on community composition were noted for the non-enriched community, with adult copepods as the only exception. Again, this is in line with our previous study, which was nutrient limited throughout the experiment, and where community composition of the dominating trophic level of phytoplankton was more severely affected compared with activity. We could have attempted to obtain larger initial differences between treatments in terms of nutrients to get clearer effect responses; however, we strived to keep additions within a range of naturally occurring concentrations, and even though the additions were modest, a difference in response towards pyrene was observed.

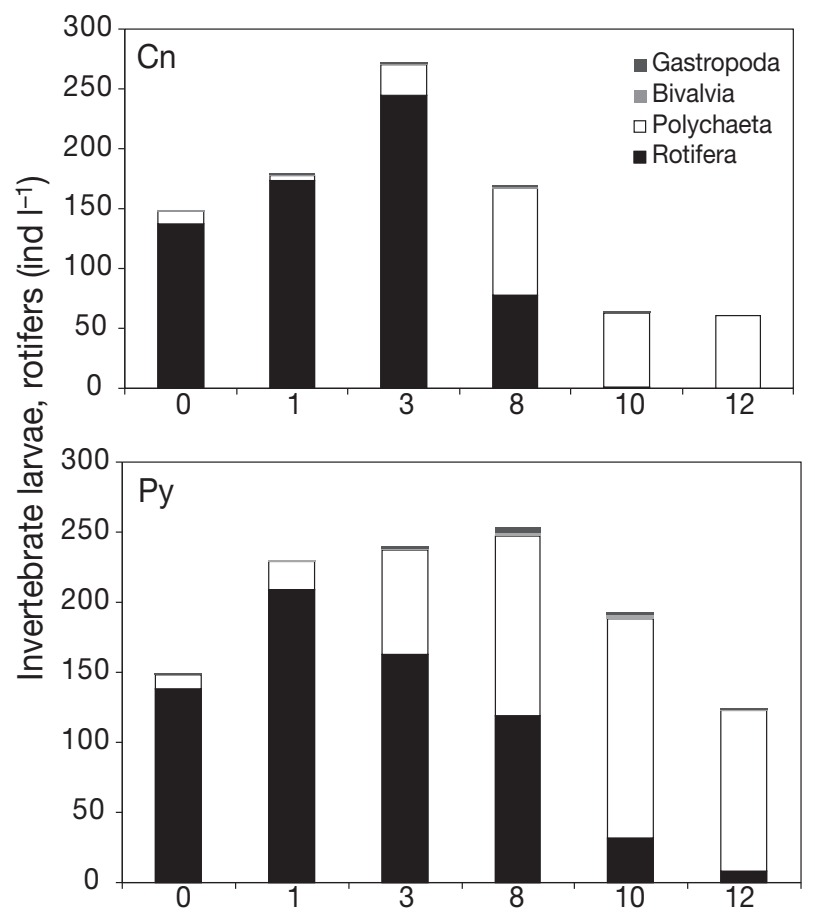

The first addition of nutrients and pyrene, as well as the combination of the two, all affected the plankton communities at the start of the experiment. Addition of nutrients increased phytoplankton abundance and activity, but did not change the algal community composition, and the bacterial activity was unaffected. Pyrene, on the other hand, immediately decreased both phytoplankton biomass and primary production, and this was evident to the highest degree in the enriched community. Algal community composition changed significantly according to pyrene exposure only on Day 1, and only for the Py communities. Diatoms dominated the communities after pyrene exposure at the expense of cryptophytes and dinoflagellates, which were more sensitive to pyrene. These results are consistent with our previous study (Hjorth et al. 2007), but contrary to other findings (Nayar et al. 2005, Sargian et al. 2005). The combination of low total photosynthetic activity and high algal specific activity up until Days 4 through 5 for Py and NuPy communities usually suggests a shift in species composition towards more tolerant species (Hjorth et al. 2007). It is unclear why the shift to more tolerant diatoms was not also evident in NuPy communities, but it should be noted that the pigment data cannot detect shifts beneath class level very well, and therefore, changes between diatom species may well have occurred.
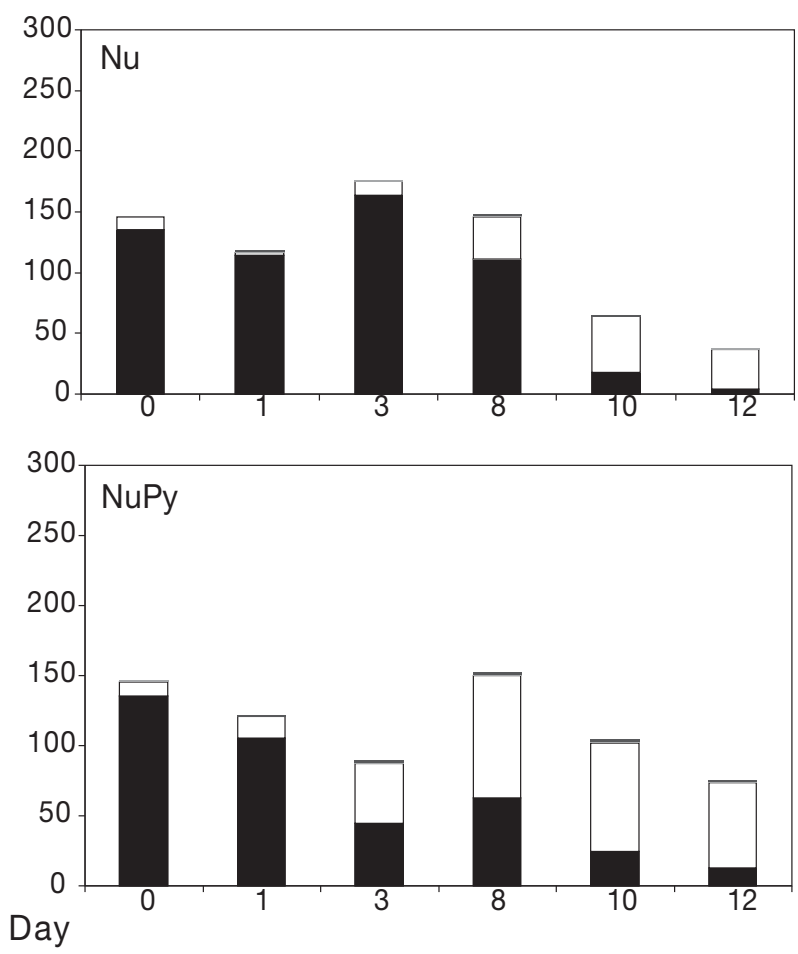

Fig. 9. Mean $\pm \mathrm{SD}(\mathrm{n}=3$ ) abundance of invertebrate larvae and rotifers in $\mathrm{Cn}, \mathrm{Nu}, \mathrm{Py}$ and NuPy (control, nutrient-enriched, pyrene-exposed and nutrient-enriched + pyrene-exposed, respectively) communities on selected days ofthe experiment 
Bacterial response to pyrene exposure was indifferent to nutrient status. In both Py and NuPy communities it followed a well-established pattern (Hjorth et al. $2006,2007)$. The rapid decline of chl a after the first pyrene exposure released substrate that led to a high bacterial activity in the pyrene-exposed communities (Fig. 6). The data suggest that bacterial growth is substrate limited and only substrate added in the form of dissolved or particulate organic matter (DOM or POM) from algal death can enhance bacterial activity as was seen in pyrene treated communities. This is consistent with what would be expected in nutrient limited systems, where dissolved organic carbon (DOC) input increases bacterial activity (Duarte \& Prairie 2005).

Surprisingly, the $\mathrm{Nu}$ communities could not sustain as high zooplankton abundance as did the Cn communities. If food were growth limiting for copepods, nutrient enriched communities ( $\mathrm{Nu}, \mathrm{NuPy})$ should, in theory, support more phytoplankton, and thus more copepods, and as the initial chlorophyll concentrations were higher in $\mathrm{Nu}$ and $\mathrm{NuPy}$ communities this could be expected. But quite the opposite occurred in regard to adult copepod numbers. In all communities copepod abundance began with low numbers and increased during the experimental period, implying constant rates of nauplii hatching and development, which is supported by the nauplii counts (data not shown). Despite this, adult copepod abundance was 0.5 to 0.8 times lower in $\mathrm{Nu}$ and NuPy communities than in $\mathrm{Cn}$ and Py communities. This could be due to differences in grazing pressure on copepod eggs between the treatments as there were observations of high numbers of microzooplankton in the $\mathrm{Nu}$ communities including ciliates and flagellates, which are known to predate on zooplankton eggs (K. W. Tang pers. comm.).

Overall, zooplankton was generally sensitive to both nutrient enrichment and pyrene exposure and all treatments were significantly different from the $\mathrm{Cn}$ communities at Day 1, but details reveal a more varied picture. Multivariate statistical analysis of zooplankton abundance data showed differences in response to pyrene depending on nutrient status when divided into developmental stages and taxonomic groups (Table 1). Adult copepods were more susceptible to the combination of nutrient and pyrene exposure. This might be a reflection of exposure pathways, where prey uptake can be expected to have been higher in NuPy communities, which contained more algal biomass, and thus copepods would be more heavily exposed. The exposure pathway through prey uptake can also explain why effects were mainly seen later on in the experiment. Invertebrate larvae, predominantly polychaete larvae and to a lesser extent gastropod and mollusc larvae, increased in abundance in both pyrene exposures. This was most evident in the pyrene only exposure, but the numbers of polychaete larvae in both Py and NuPy communities were between 2 and 3 times higher than in the unexposed communities (Fig. 9). This could be an indication of higher tolerance or lower pyrene uptake of polychaete larvae compared with copepods, but it could just as well have come from a change in predation pressure from microzooplankton.

The second nutrient addition was only visible in the $\mathrm{Nu}$ communities as a brief increase in chl a immediately followed by a sharp decline. The general low biomass and production levels in all communities at the time led to a poor detection of effects with the methods used, and may explain some of the lack of effects from the second nutrient spiking and pyrene exposure on phytoplankton communities. The only indication of a response to the second pyrene exposure was in the bacterial production, with a slight increase in the NuPy communities, again indicating a higher availability of substrate, although it could not be confirmed in a simultaneous reduction in chl a. However, at this point the plankton communities had developed into topdown controlled systems, where zooplankton increased more than 8-fold over the first $8 \mathrm{~d}$, while phytoplankton decreased. The lack of phytoplankton and bacterial response to the second exposure of pyrene and nutrient enrichment could have been due to the heavy top-down control by high numbers of zooplankton grazing down phytoplankton to low levels, especially as there was no apparent lack of substrate for the bacteria or phytoplankton to explain the low response. However, it cannot be excluded that zooplankton actually were affected by the second exposure and that the effect seen at the end of the experiment could have been a result of both the first and second exposures.

Alternatively, the apparent lack of response to the second pyrene exposure from phytoplankton could be due to a selection pressure on the communities in favour of tolerant species and/or activities from the first pyrene exposure. At the time of the second addition, the sensitive components in the communities were already removed and a lower response to the second stress was to be expected. This could not be confirmed by the diversity analyses.

Interactions between trophic levels, abiotic factors and contaminants in this mesocosm study might easily have been ignored if an extensive array of endpoints had not been applied. Even so, more details in terms of the choice of endpoints and organism groups investigated can further enhance our understanding of contaminant stress effects on plankton communities. In studies of contaminant effects at community level, a combination of structural and functional endpoints of the selected trophic levels must be assessed to gain a proper understanding of the dynamics in plankton sys- 
tems under stress. The system dynamic, also in terms of bottom-up or top-down control, is even more important to understand when trying to extrapolate experimental effects to the natural environment, where biotic and abiotic changes are normal.

\section{CONCLUSIONS}

The results demonstrate that pulses of pyrene exposure affects functional and structural variables at several trophic levels in marine plankton in different ways according to the nutrient conditions of the system. Short-term effects were most evident on the phytoplankton community, whereas long-term effects appeared in the zooplankton community. Nutrient enrichment differentiated the zooplankton communities at the beginning and thereby changed the effects of pyrene in most of the investigated trophic groups compared with the control. The relative magnitude of early and late responses to pyrene can be modified by nutrient status, which has implications for assessing risk of $\mathrm{PAH}$ exposure to plankton ecosystems in eutrophicated areas, since it is imperative to our understanding of contaminant effects on natural communities that interactions between trophic levels and between chemicals and abiotic factors are included.

Acknowledgements. This work was partly funded by a $\mathrm{PhD}$ fellowship from Roskilde University and the National Environmental Research Institute, Department of Marine Ecology, and partly from the European Union project Thresholds of Environmental Sustainability (Contract No. 003933). Thanks to H. J. Olsen (Søminen field station) and G. Jacobsen, D. W. Jensen, L. Renvald and P. Kofoed (NERI) for practical assistance. Associate Professor K. W. Tang, Virginia Institute of Marine Science, and collaborators are thanked for a fruitful cooperation and co-financing of the mesocosm experiment.

\section{LITERATURE CITED}

Andersen J, Markager SS, Ærtebjerg G (2004) Tekniske anvisninger for marin overvågning. 2.2 Vandkemiske parametre. National Environmental Research Institute, Department of Marine Ecology, Roskilde

Bignert A, Cossa D, Emmerson R, Fryer R and others (2004) OSPAR/ICES workshop on the evaluation and update of background reference concentrations (B/RCs) and ecotoxicological assessment criteria (EACs) and how these assessment tools should be used in assessing contaminants in water, sediment, and biota. OSPAR Commission,

Editorial responsibility: Otto Kinne, Oldendorf/Luhe, Germany
Final Report of Workshop, 9-13 February 2004, The Hague

Cloern JE (2001) Our evolving conceptual model of the coastal eutrophication problem. Mar Ecol Prog Ser 210: 223-253

> Duarte CM, Prairie YT (2005) Prevalence of heterotrophy and atmospheric $\mathrm{CO}_{2}$ emissions from aquatic ecosystems. Ecosystems 8:862-870

Egge JK, Heimdal BR (1994) Blooms of phytoplankton including Emiliania huxleyi (Haptophyta). Effects of nutrient supply in different N:Py ratios. Sarsia 79:333-348

- Fleeger JW, Carman KR, Nisbet RM (2003) Indirect effects of contaminants in aquatic ecosystems. Sci Total Environ 317:207-233

- Harley CDG, Hughes AR, Hultgren KM, Miner BG and others (2006) The impact of climate change in coastal marine systems. Ecol Lett 9:228-241

> Hjorth M, Forbes VE, Dahllöf I (2006) Effects on the function of three trophic levels in marine plankton communities under stress from the antifouling compound zinc pyrithione. Aquat Toxicol 77:105-115

Hjorth M, Vester J, Henriksen P, Forbes V, Dahllöf I (2007) Functional and structural responses of marine plankton food webs to pyrene contamination. Mar Ecol Prog Ser 338: 21-31

Interlandi SJ (2002) Nutrient-toxicant interactions in natural and constructed phytoplankton communities: results of experiments in semi-continuous and batch culture. Aquat Toxicol 61:35-51

Koelmans AA, Heijde Van Der A, Knijff LM, Aalderink RH (2001) Integrated modelling of eutrophication and organic contaminant fate and effects in aquatic ecosystems. A review. Water Res 35:3517-3536

> Macdonald RW, Harner T, Fyfe J (2005) Recent climate change in the Arctic and its impact on contaminant pathways and interpretation of temporal trend data. Sci Total Environ 342:5-86

> Nayar S, Goh BPL, Chou LM (2005) Environmental impacts of diesel fuel on bacteria and phytoplankton in a tropical estuary assessed using in situ mesocosms. Ecotoxicology $14: 397-412$

Preston BL (2002) Indirect effects in aquatic ecotoxicology: implications for ecological risk assessment. Environ Manag 29:311-323

> Sargian P, Mostajir B, Chatila K, Ferreyra GA, Pelletier E, Demers S (2005) Non-synergistic effects of water-soluble crude oil and enhanced ultraviolet-B radiation on a natural plankton assemblage. Mar Ecol Prog Ser 294: $63-77$

Skei J, Larsson P, Rosenberg R, Jonsson P, Olsson M, Broman D (2000) Eutrophication and contaminants in aquatic ecosystems. Ambio 29:184-194

Smith DC, Azam F (1992) A simple, economical method for measuring bacterial protein synthesis rates in seawater using ${ }^{3} \mathrm{H}$-leucine. Mar Microb Food Webs 6:107-114

Sundbäck K, Petersen DG, Dahllöf I, Larson F (2007) Combined nutrient-toxicant effects on a shallow-water sediment system: sensitivity and resilience of ecosystem functions. Mar Ecol Prog Ser 330:13-30

Submitted: May 15, 2007; Accepted: February 22, 2008 Proofs received from author(s): June 19, 2008 